\title{
RELAÇÃO ENTRE APRENDIZAGEM, AVALIAÇÃO E O SISTEMA DE CICLOS
}

\section{THE RELATIONSHIP BETWEEN LEARNING, ASSESSMENT AND THE CYCLES SYSTEM}

\author{
Cíntia de Andrade Nunes ${ }^{1}$ \\ Fundação Municipal de Educação de Niterói - RJ \\ ORCID: https://orcid.org/0000-0002-8559-8632 \\ Vânia Finholdt Ângelo Leite ${ }^{2}$ \\ Universidade Estadual do Rio de Janeiro - UERJ \\ ORCID:https://orcid.org/0000-0003-4583-7165
}

\section{RESUMO}

A organização do tempo escolar em ciclos, em alguns municípios, foi apresentada como uma alternativa para o sistema seriado, no qual, como sabemos, os alunos têm o seu aprendizado avaliado por meio de provas. No entanto, mesmo sem a temida possibilidade de reprovação anual, o nível de aprendizado dos estudantes ainda está abaixo do esperado. Assim, este artigo visa responder às seguintes questões: O que fazer para melhorar a aprendizagem no sistema de ciclos? Qual deve ser o lugar da avaliação da aprendizagem nessa nova organização do tempo escolar? A fim de responder a tais questões, analisaram-se cinco revisões e um artigo de pesquisadores da organização do tempo escolar em ciclos no Brasil. Esses trabalhos foram publicados em eventos reconhecidos nacionalmente e em revistas bem conceituadas na comunidade científica e convergem para a opinião de que a mudança de séries para ciclos exige que o conceito de avaliação formativa seja posto em prática, assim como a reorganização do currículo. Assim, é necessário propiciar tempo para que os docentes possam estudar e aperfeiçoar seu trabalho. Ademais, para reorganizar o currículo, é fundamental elaborar propostas pedagógicas diferenciadas por equipes de professores e gestores e proporcionar a participação dos demais funcionários, dos estudantes e de suas famílias.

Palavras-chave: Avaliação. Ciclo de formação. Aprendizagem.

\section{INTRODUÇÃO}

A organização do tempo escolar em ciclos, em alguns municípios, foi apresentada como uma alternativa para o sistema seriado, no qual, como sabemos, a aprendizagem dos alunos é avaliada por meio de provas. No entanto, mesmo sem a temida possibilidade de reprovação anual, o nível de aprendizado dos alunos ainda está abaixo do esperado. Nossa experiência docente mostra que, na Rede Municipal de Niterói, tivemos alunos que, no quarto ano, ainda não sabiam ler nem escrever. Barreto

\footnotetext{
${ }^{1}$ Especialista em Educação Básica (Gestão Escolar) pela Universidade do Estado do Rio de Janeiro (UERJ); leciona em escolas da Fundação Municipal de Educação de Niterói/RJ. E-mail: cintianunes@id.uff.br

${ }^{2}$ Doutora em Ciências Humanas - Educação, na Pontifícia Universidade Católica do Rio de Janeiro (PUC-Rio); leciona na Universidade Estadual do Rio de Janeiro (UERJ), na Faculdade de Formação de Professores, nos cursos de graduação e pós-graduação. São Gonçalo/ RJ. E-mail: vfaleite@uol.com.br
} 
e Sousa (2005) apontam o que é necessário para que o ciclo possa contribuir para que a maioria dos alunos aprenda:

A reorganização escolar impõe condições do ponto de vista dos recursos humanos, materiais e pedagógicos que, se não atendidas, esvaziam o potencial que têm os ciclos de constituírem alternativa capaz de contribuir para a democratização do ensino. (BARRETO; SOUSA, 2005, p. 682)

Assim, este trabalho objetiva analisar alguns artigos sobre esse assunto, publicados por revistas científicas, como a Revista Brasileira de Educação, Ensaio: Avaliação e Políticas Públicas em Educação, Educação e Pesquisa, a fim de constituir uma síntese das principais dificuldades que os professores têm de implementar o processo de avaliação dos alunos e de compreender esse processo. E como o sistema ciclado limita a possibilidade de os alunos serem reprovados no final de cada ciclo ou de não apresentarem frequência mínima à escola, o que coloca em questão a prática de avaliação, este trabalho busca uma resposta para as seguintes perguntas: $\mathrm{O}$ que fazer para melhorar a aprendizagem no sistema de ciclos? Qual deve ser o lugar da avaliação da aprendizagem nessa nova organização do tempo escolar? Para respondê-las, usamos como referência textos, vídeos e entrevistas de autores como Esteban (2001, 2003, 2009), Freitas (2005), Luckesi (2000) e Paro (2002). As informações mais relevantes encontradas no material selecionado foram analisadas com base nos estudos de Esteban, porque focam a avaliação da aprendizagem.

Como podemos notar, a questão dos ciclos está diretamente ligada à avaliação.

As escolas públicas brasileiras tendem a reproduzir o lugar social dos seus alunos. A partir dos anos 1950, os filhos das classes populares passaram a frequentar a escola de forma massiva, o que não significa acesso a um ensino de boa qualidade. Foi por meio das avaliações que a opressão do ensino aos advindos das classes menos favorecidas ficou evidente. Maria Teresa Esteban (2009), renomada pesquisadora do processo de avaliação escolar, assevera que a escola desvaloriza as múltiplas aprendizagens desses alunos e suas diferentes experiências e interações cotidianas, ou seja, seu conhecimento de mundo. Nossas avaliações hierarquizam, classificam e apagam as singularidades e buscam uma homogeneidade. Segundo Esteban (2009), o erro costuma ser encarado de maneira equivocada. Ela entende que, ao errar, os alunos não demonstram incapacidade, mas o que já foi aprendido e o que ainda precisam aprender. 
A autora constata que o desempenho escolar insuficiente é analisado como fruto de ações individuais, não como fracasso de um projeto. Os resultados dos exames internacionais, dos nacionais e dos que são realizados no cotidiano escolar denunciam a exclusão do diferente, porquanto eles revelam a concentração de baixo desempenho justamente nos grupos subalternizados. Assim, verificamos que só houve uma democratização no acesso e que a exclusão, agora, ocorre no interior da escola.

As práticas pedagógicas [...] atuam no sentido de destituir os sujeitos de sua cultura, valores, conhecimentos, modos de reprodução da realidade, de solução de problemas, de enfrentamento de conflitos, [...] se reduzem a buscar levar os estudantes ao bom desempenho, garantido pela reprodução dos processos e produtos que conformam o padrão a ser alcançado. (ESTEBAN, 2009 p.131)

Como vimos, em vez de incluir, a escola exclui, ao negar os conhecimentos dos estudantes mais pobres. Associa-se um melhor sistema de exame a um melhor sistema de ensino. Podemos observar uma crescente preocupação com a consolidação e o refinamento de exames e de notas. A autora ressalta que avaliar significa atribuir valor, por isso é fundamental refletir não só sobre os procedimentos utilizados, mas também, principalmente, valores que orientam o atual processo pedagógico.

Em uma entrevista para o programa Salto para o futuro (2004), Esteban asseverou que qualquer grupo é marcado pela diferença e que essa é uma característica da sala de aula. Então, não há razão para tentarmos formar turmas homogêneas. Ela explica que a heterogeneidade potencializa, pois, quanto mais diferentes nós formos, mais temos a ensinar e a aprender uns com os outros, e quando tentamos padronizar, reduzimos essa potencialidade. Portanto, o ideal é que a avaliação seja uma prática de investigação. Ainda na mesma entrevista, ela afirma: “ [...] A avaliação não é responsável nem pelo fracasso escolar, nem pela exclusão social e, portanto, não é apenas mudando os procedimentos de avaliação que nós vamos produzir sucesso escolar e inclusão social." Sendo assim, não podemos dizerque osistema seriado, em que os alunos passam por avaliações classificatórias pelo menos três vezes por ano, garante que eles aprendam.

É muito comum ouvirmos de pais e de outros professores que as séries funcionam melhor do que os ciclos e que a possibilidade de repetir o ano letivo induz os estudantes a se interessarem mais pelos estudos. De acordo com Paro (2002), o 
problema não está na retirada da reprovação, mas que a raiz do problema continua sendo a mesma: a qualidade ${ }^{3}$ do ensino. Ele enuncia que, embora

essa prática coíba o vício reprovador, nada mais acrescenta para a superação do mau ensino. [...] A diferença é que agora ele passa a incomodar as pessoas, levando os mal informados a porem a culpa pelo mau ensino na progressão continuada. Mas o aluno deixa de aprender, não porque foi aprovado, mas porque o ensino é ruim, coisa que vem acontecendo desde muito antes de se adotar a progressão continuada. Apenas que, antes, esse mesmo aluno permanecia na primeira série, ou se evadia, tão ou mais analfabeto que agora. Mas aí era cômodo, porque ele deixava de constituir problema para o sistema de ensino. Agora, com a aprovação, percebe-se a reiterada incompetência da escola. (PARO, 2002, p.2)

Como podemos observar, para o autor supracitado, o sistema de ciclos está sendo criticado porque evidencia que a escola não tem cumprido com o seu papel, que seria o de levar o aluno a querer aprender. Luckesi (2000) também destaca a necessidade de uma formação mais consistente para os professores, além das condições salariais e da organização escolar, para que os ciclos de formação sejam bem-sucedidos.

Freitas (2005) enuncia que a organização curricular em ciclos, uma das modalidades facultadas pela LDBEN 9.394/1996, art.23, permite concepções diversas:

A educação básica poderá organizar-se em séries anuais, períodos semestrais, ciclos, alternância regular de períodos de estudos, grupos não seriados, com base na idade, na competência e em outros critérios, ou por forma diversa de organização, sempre que o interesse do processo de aprendizagem assim o recomendar. (LDBEN, 9.394/1996)

Nas palavras dessa autora, é o projeto político-pedagógico da escola que irá definir a compreensão assumida e responder a questões como: Ciclos de quê? Ciclos paraquê?Assim,elaressaltaqueaexpressão“organizaçãocurricularporciclos”requer sua complementação adjetiva.

Freitas (2005) chama à atenção para o fato de que eliminar a possibilidade de reprovação é muito importante, já que essa prática é um fator de exclusão que gera frustração, baixa autoestima e sentimento de inferioridade. Porém isso não é suficiente.

\footnotetext{
${ }^{3} \mathrm{Na}$ concepção de Paro (2002), ensino de boa qualidade é aquele em que o aluno não é reprovado no final do ano, portanto não tem novamente o mesmo conteúdo, o mesmo professor, com os mesmos métodos. Ou seja, um ensino em que o aluno não é o único considerado culpado por não aprender, visto que a atividade pedagógica que se dá na escola envolve uma série de fatores como: as políticas públicas, os professores e seu salário, suas condições de trabalho, o material didático disponível etc.
} 
Seu trabalho salienta que, para que haja aprendizagem para todos, é preciso romper com a padronização do ensino e criar mecanismos que garantam o apoio necessário para isso.

Com o objetivo de responder a estas perguntas: O que fazer para melhorar a aprendizagem no sistema de ciclos? Qual deve ser o lugar da avaliação da aprendizagem nessa nova organização do tempo escolar?, faremos, a seguir, uma breve consideração sobre a prática de avaliação escolar, analisando algumas questões que têm surgido com a implantação do sistema de ciclos e, em seguida, a análise do corpus. Por último, apresentamos as considerações finais.

\title{
2 AVALIAÇÃO, APRENDIZAGEM E O SISTEMA DE CICLOS
}

Nesta seção, trazemos uma abordagem sobre a relação entre avaliação, aprendizagem e o sistema de ciclos. Esteban (2001, p.175) refere que

\begin{abstract}
o movimento que caracteriza as práticas escolares cotidianas explicita a impossibilidade de se reduzir avaliação a um conjunto de momentos estanques que costuram fragmentos do processo de ensino/aprendizagem, perspectiva que limita (quando não impede) a possibilidade de os sujeitos construírem conhecimentos num movimento dialógico. [...] Incorporar a heterogeneidade de saberes presentes na vida escolar exige que a lógica da avaliação se aproxime a um dinâmico caleidoscópio em que o resultado se transforma segundo os movimentos que conduzem a (re)articulação dos fragmentos.
\end{abstract}

A autora explica que, apesar de se entender que a avaliação deve ser um processo permanente, marcado por continuidades, por rupturas e por processos, muitos professores insistem em práticas que não favorecem o aprendizado, como, por exemplo, a atuação pedagógica guiada exclusivamente por livros didáticos e avaliações cujo principal objetivo é de punir e o planejamento sem apoio nos resultados da avaliação.

Apesar da diversidade na formulação dos $\operatorname{ciclos}{ }^{4}$, podemos dizer, conforme Barreto \& Sousa (2005), que um dos princípios fundamentais dessa política é a redução de retenções, o que contribui para preservar a autoestima dos alunos ao respeitar suas diferenças e diminuir a evasão escolar infantil. Além disso, os ciclos fazem com que os

\footnotetext{
${ }^{4}$ De acordo com Mainardes (2009), a partir dos anos 1990, diversas modalidades de ciclos foram elaboradas, e diferentes denominações têm sido utilizadas para se referir à organização da escola em ciclos no Brasil, como: Ciclo Básico, Ciclos de Aprendizagem, Ciclos de Formação Humana, Regime de Progressão Continuada, Bloco Inicial de Alfabetização, Ciclo Complementar de Alfabetização, Ciclos de Ensino Fundamental e Organização em Ciclos.
} 
alunos passem mais tempo na escola do que na rua, o que é muito bom, principalmente para os que residem em áreas com alto índice de violência.

Ressalte-se, contudo, que a adoção da política mencionada no parágrafo acima tem causado polêmica, principalmente entre os educadores. Nas redes que implantaram ciclos, a principal queixa é de que as escolas não possuem os recursos necessários para fazer as mudanças pretendidas. Outra questão é que, devido à progressão proporcionada pelo sistema ciclado, é recorrente o fato de alunos chegarem aos ciclos finais sem saber ler e escrever, e até os professores de Língua Portuguesa não se sentem preparados para lidar com essa realidade, porque não recebem formação para isso (BARRETO; SOUSA, 2005).

Entre as mudanças que ocorrem na escola, a avaliação é a que tem se destacado nas escolas com ciclos. A ideia de suprimir a reprovação do aluno tem encontrado resistência, sobretudo entre profissionais da área e pais. Para os professores, seu trabalho fica mais difícil. “ [...] A reprovação é reivindicada como um mecanismo necessário para garantir a aprendizagem, sendo a ela atribuído um potencial de motivação para o ensino e a aprendizagem" (BARRETO; SOUSA, 2005, p. $675 \quad$ ). O sistema de ciclos nos leva a refletir sobre a finalidade da avaliação, que tem sido utilizada com a intenção de classificar, reter ou promover o estudante para o próximo ano escolar. E como o objetivo do sistema de ciclos é de democratizar a permanência na escola e de superar seu caráter seletivo, apresentamos estas considerações de Sousa (2000, apud BARRETO; SOUSA, 2005, p. 675).

Os estudiosos insistem que os ciclos geram a imperiosa necessidade de que a avaliação se constitua em atividade de acompanhamento e promoção dos alunos. Alertam, contudo, para o fato de que a exclusão escolar e social pode estar sendo intensificada com os ciclos, ainda que não visível sob as estatísticas de aprovação, sempre que não estejam criadas condições de efetiva aprendizagem para todos os alunos.

Essa citação ressalta que há uma ligação direta entre aprendizagem, avaliação e o sistema de ciclos e sinaliza que, quando não se instaura um processo de avaliação da aprendizagem que ofereça aos alunos condições de terem uma aprendizagem real, ou seja, uma avaliação formativa, os ciclos podem reforçar a exclusão escolar e social.

\section{METODOLOGIA}


As revisões selecionadas abrangem o período de 1980 a 2010. O material analisado pelos autores foram teses, dissertações e artigos sobre ciclos e progressão continuada. Os autores das revisões - Barreto e Sousa (2004), Gomes (2004), Jacomini (2014) e Mainardes $(2008,2009)$ - são pesquisadores brasileiros especialistas no tema. Além disso, os artigos analisados foram publicados em eventos reconhecidos nacionalmente e em revistas classificadas pela CAPES como A1. Isso significa que são periódicos reconhecidos na comunidade científica.

Além dessas cinco revisões, selecionamos o artigo de Cunha (2004), porquanto ele aborda práticas avaliativas bem-sucedidas. É importante ressaltar que os achados desta pesquisa não separam o tipo de modelo de ciclo implementado porque as teses e as dissertações utilizadas nos artigos analisados - cinco artigos - não indicaram o modelo. Somente o artigo de Jacomini (2014) se refere à progressão continuada.

Os artigos selecionados foram analisados com base nas seguintes categorias: a Condições de trabalho; b - Gestão da escola e participação de todos; c - Prática pedagógica e avaliação e d - O processo de implementação dos ciclos. Apesar de separadas para a apresentação da análise, elas estão inter-relacionadas na prática dos professores.

Explicaremos suscintamente o que compreendemos por cada categoria:

a - Condições de trabalho - Nessa categoria, foi incluído tudo o que se refere às condições os docentes para desenvolver suas atividades na sala de aula e na escola, dentre elas, incluímos a formação continuada.

b - Gestão da escola e participação de todos - aqui foram incluídos os aspectos que favorecem as mudanças no currículo e na avaliação com a discussão da equipe pedagógica, professores, dos funcionários e dos pais.

c - Prática pedagógica e avaliação - essa categoria trata das mudanças nas práticas e nas ações dos professores em relação à avaliação.

d - Processo de implementação dos ciclos - categoria em que se apontam tentativas e implementações bem-sucedidas do sistema de ciclos.

\section{ANÁLISE DO CORPUS}

Os seis artigos selecionados falam sobre condições de trabalho, gestão da escola, participação de todos, avaliação, prática pedagógica e processo de implementação de ciclos. Fizemos um resumo dessas categorias a fim de tentar responder às questões iniciais. 


\subsection{Condições de trabalho}

Reafirmamos que este tópico trata das condições que os docentes têm para desenvolver suas atividades na sala de aula e na escola, como por exemplo, a formação continuada.

A análise de Mainardes (2008) constata que diversas pesquisas indicam a necessidade de aprimorar as estratégias de formação permanente dos professores, visto que elas têm sido frágeis e insuficientes para lhes garantir um domínio profundo e abrangente das questões teórico-práticas referentes à avaliação da aprendizagem no sistema ciclado. $\mathrm{O}$ autor citado argumenta que a formação docente poderia incluir as seguintes questões:

[...] a) a importância da utilização de estratégias de avaliação com critérios claros e explícitos, com o objetivo de se obter informações sobre o processo de aprendizagem dos alunos; b) o uso das informações obtidas por meio da avaliação para reorientar o processo de ensino [...] e c) a construção coletiva de formas de registros de avaliação e a da aprendizagem que sejam mais coerentes com o caráter formativo e emancipador da avaliação. (MAINARDES, 2008, p.12)

Considerando que o ato de avaliar é inerente ao processo de ensino/aprendizagem, Esteban (2003) sugere que deveríamos romper com as dicotomias erro/acerto e saber/não saber. Para ela, esses conceitos não são opostos, mas complementares. Se essas questões fossem mais trabalhadas na formação, como indica Mainardes (2008), o docente poderia utilizar a avaliação e seus registros, com o objetivo de diagnosticar o que o aluno ainda não sabe para propor uma atividade que o ajudasse a avançar na aprendizagem.

Nesse sentido, a avaliação passa a ser uma prática de investigação. Nas palavras de Esteban, “ [...] ao dialogar com o aluno, ainda que brevemente, e ao se dispor a aprender com ele, o professor desfaz muros e restabelece laços" (ESTEBAN, 2003, p.18). Essas mudanças na avaliação poderiam consolidar práticas pedagógicas democráticas, como é proposto pelo sistema de ciclos.

Ao falar sobre os aspectos que favorecem os ciclos, Gomes (2004) também afirma que é necessária uma formação continuada eficaz na escola, e não, em programas de massa, além de jornada ampliada. Nas revisões analisadas, constatamos que os aspectos apontados por Gomes (2004) foram realizados nas redes dos municípios de São Paulo e de Minas Gerais que, por exemplo, proporcionaram aos professores um horário para estudarem e reunião para que pudessem pensar e planejar sua práticapedagógica:“ [...] 
Entre as condições propiciadas para dar suporte à nova organização curricular, destacam-se: a criação de horários coletivos de trabalho na escola, [...] a jornada de trabalhointegral"'(BARRETO;SOUSA,2004,p.39).

As condições de trabalho da Escola Plural, em Belo Horizonte, também oportunizaram o trabalho docente: “[...] tempos remunerados de estudo e pesquisa, expressão da consciência dos profissionais sobre o desempenho no trabalho [...] alarga se também a concepção de formação profissional continuada" (BARRETO; SOUSA, 2004, p. 41). Como vimos, mudanças nas condições de trabalho são fundamentais para que a organização dos anos escolares em ciclos possa ser bem-sucedida. Não basta eliminar a reprovação anual. Os professores precisam de tempo para estudar e aperfeiçoar seu trabalho, porque os ciclos exigem reorganização do currículo e mudanças na avaliação da aprendizagem, como: deixar de ser classificatória e tornar-se formativa, buscando informações sobre o processo de aprendizagem dos alunos e deixando de buscar sua homogeneidade.

\subsection{Gestão da escola e participação de todos}

Neste subtópico, apresentamos alguns aspectos da gestão que favorecem mudanças no currículo e na avaliação da aprendizagem no sistema de ciclos. O trabalho de Jacomini (2014, p.821) aponta as seguintes condições para que a implantação do sistema de ciclos seja bem-sucedida em relação à gestão:

(a) a manutenção das equipes de professores e gestores na escola para a construção de propostas pedagógicas diferenciadas; (b) a discussão das políticas educacionais com os educadores e a comunidade escolar para sua efetiva implementação.

Gomes (2004) também constatou nas pesquisas que são insuficientes as ações nas escolas para persuadir e cativar os atores principais - os professores, os alunos e suas famílias - durante a implementação dos ciclos. O autor (2004) entende que, sem a participação desses atores principais, "as melhores concepções pedagógicas e as melhores medidas da gestão frustram-se se os professores não são persuadidos e preparadosparalevaraefeitodeterminadasinovações”(GOMES,2004,p.42). Sobrea

participação da família e dos alunos, ele argumenta:

Quanto aos pais, junto com os alunos, sobretudo a partir de certa idade, eles têm aspirações sociais importantes em face da escolaridade e decidem sair ou permanecer nela, arcando com os seus custos, 
mesmo os de oportunidade (isto é, de cursar a escola em vez de fazer outra coisa) (GOMES, 2004, p.42).

Esse fragmento mostra a influência dos pais sobre os filhos e, por isso, evidencia a importância da participação de todos como um aspecto favorável à implementação dos ciclos. Nas revisões, encontramos um exemplo de rede que teve a participação de to dos - a de Porto Alegre. De acordo com Barreto e Sousa (2004), lá a reorganização curricularocorreudevido ao “ [...] envolvimento de alunos, famílias e funcionários na discussão do currículo"(BAR RETO; SOUSA, 2004, p. 44).

Em síntese, esta seção assinalou mais algumas medidas para a implementação dos ciclos nas escolas, a saber: a elaboração de propostas pedagógicas diferenciadas por equipes de professores e gestores e a participação dos demais funcionários, de estudantes e de suas famílias na reorganização do currículo.

\subsection{Prática pedagógica e avaliação}

Nesta parte, tratamos das mudanças que ocorreram nas práticas avaliativas e do que ainda precisa ser feito a partir das revisões das pesquisas. A revisão de Jacomini (2014) e a de Mainardes (2009) chamam à atenção para o fato de que os professores não compreenderam o conceito de avaliação formativa e reiteram seu uso para a tomada de decisão sobre promoção e reprovação dos alunos, em vez de utilizá-la como uma ferramenta de investigação para melhorar sua prática. Selecionamos um trecho que demonstra isso:

[...] Diversos trabalhos apontaram as dificuldades que muitos professores encontravam para romper com o modelo de avaliação tradicional [...] bem como para utilizar as informações obtidas pela avaliação no redimensionamento do processo ensino - aprendizagem. (MAINARDES, 2009, p.11).

Já discutimos a esse respeito no subtópico 'C ondições de trabalho'. Esteban (2003) afirma que muitas das propostas atuais de reformulação da prática avaliativa não abandonam a prática de classificação:

[...] Sob outros formatos e outros instrumentos são sustentadas as mesmas finalidades da avaliação. $O$ contexto escolar adquire certo grau de liberdade, mas os processos pedagógicos continuam vinculados a um produto determinado (ESTEBAN, 2003, p.13).

Mainardes (2009) lembra que o estudo de Souza (2005) “ $\quad[\ldots]$ constatou que, embora as taxas de evasão e reprovação tenham diminuído com a implantação dos 
ciclos, 'o não aprender' se configura no cotidiano da sala de aul a" (MAINARDES, 2009, p.11). Os trabalhos citados acima mostram que já foram feitas algumas mudanças, mas a finalidade avaliativa continua a mesma, visto que grande parte das propostas atuais de avaliação da aprendizagem tem como objetivo a classificação. Isso não contribui para o aprendizado dos estudantes e mostra que alguns professores têm dificuldade de compreender o conceito de avaliação formativa.

Essas mudanças apontadas por Esteban (2003) não são tão fáceis e rápidas de praticar. Jacomini (2014) também afirma que houve mudanças no discurso sobre a avaliação, mas nãona prática dos docentes:“ [ [...] embora as concepções de avaliação não tradicionais estejam presentes na escola, sua presença no fazer pedagógico é bastante desigual"(JACOMINI,2014,p.821).

A sociedade e a escola são caracterizadas pela multiplicidade. Afinal, somos seres únicos, heterogêneos. Por isso não podemos esperar as mesmas respostas, os mesmos comportamentos. De acordo com Esteban (2003), o erro permite o professor transformar a avaliação em um processo de investigação. Encarar o erro como um indício do processo de construção de conhecimentos contribui para que o docente

[...] reflita sobre seu contexto, sobre o processo de aprendizagem /desenvolvimento de seus alunos, sobre sua atuação profissional e sobre seu próprio processo de construção de conhecimentos. (ESTEBAN, 1997, apud ESTEBAN, 2003, p. 22).

Ao transformar a avaliação de uma prática de classificação em um processo de investigação, o professor tem a possibilidade de exercitar e desenvolver conhecimentos, a fim de intervir, conforme as necessidades dos alunos, de maneira individual e coletiva. Ao romper com a avaliação como um processo de classificação, “[...] as respostas predeterminadas cedem lugar às respostas em constante construção, desconstrução e reconstrução, que passam a configurar o início de novos questionamentos, sejam elas certas ou erradas"(ESTEBAN,2003,p.22) Talatitude, segundoa autora em tela, faz com que as diferenças entre os alunos sejam entendidas como peculiaridades a serem trabalhadas e incorporadas pelo coletivo, e não mais, como deficiências que precisam ser superadas. Além disso, ressalta a importância de se considerar o conhecimento como algo inacabado, já que sua construção é permanente.

Em relação à avaliação da aprendizagem, Mainardes (2008) também conclui que a troca na organização do tempo escolar de séries para ciclos induziu a mudanças nas práticas avaliativas, mas ainda é preciso avançar: 
As formas de registro utilizadas nos programas de ciclos (fichas, pareceres descritivos, relatórios descritivos) são qualitativamente superiores às notas ou conceitos. [...] Não raro, os critérios de avaliação utilizados não estão muito claros para os professores e discrepâncias entre o registro feito pelo professor e o nível de aprendizagem real dos alunos podem ser observadas. (MAINARDES, 2008, p.8,9)

Em um trabalho publicado posteriormente, Mainardes (2009) acrescenta “[...] que muitos professores encontravam dificuldades para romper com o modelo de avaliação tradicional e com os parâmetros da seriação, para implementar modelos de avaliação formativa [...]" (MAINARDES, 2009, p.11). Podemos inferir que essa dificuldade dos docentes talvez exista pelo fato de não terem condições de trabalho adequadas, porque a formação na escola nem sempre atende às necessidades e às demandas dos ciclos, como já discutimos.

Assim, para que haja esse rompimento para avaliar a formação na escola, é preciso discutir com os docentes, por exemplo, sobre a concepção de erro. Reafirmamos, de acordo com Esteban (2009), que erro não significa incapacidade, mas o estudante ainda precisa aprender. A autora afirma que precisamos de processos avaliativos mais democráticos. Isso significa que os professores devem entender a avaliação como uma oportunidade de verificar o que o estudante ainda não sabe, as dificuldades que apresenta, e não, como um julgamento,um“acertodecontas”.

[...] a avaliação da aprendizagem precisa ter seu centro deslocado da homogeneidade, garantida pelos objetivos uniformes e necessária à classificação que permite a seleção e a exclusão. [...] Pois o erro, longe de ser expressão de não aprendizagem e de incapacidade, é expressão da relação entre o que já foi aprendido e as aprendizagens que ainda se fazem necessárias. (ESTEBAN, 2009, p. 133)

Em uma revisão, Barreto e Sousa (2004) mostram que a Escola Plural (BH), assim como as do município de Porto Alegre, apresentou, na época analisada, uma proposta mais coerente de avaliação. Podemos dizer que, em Belo Horizonte, os estudantes passavam por um processo avaliativo, porque a avaliação era feita com uma série de instrumentos variados. Ademais, estava prevista para o final do ciclo a possibilidade de reter alunos em casos especiais. No entanto, essa retenção era limitada e visava não gerar uma distorção entre a série e a idade do aluno.

As escolas municipais de Porto Alegre privilegiaram a função formativa da avaliação, que deveria funcionar como apoio ao redimensionamento da ação pedagógica e educativa (BARRETO; SOUSA, 2004, p.42, 44). Em relação à prática pedagógica 
nessa cidade, no período analisado (início dos anos 1990 em diante), foi feita de maneira coletiva, ou seja, todos da escola eram responsáveis pelo aluno.

[...] entre as condições propiciadas para garantir a reorganização curricular destacam-se: espaço/tempo para o trabalho coletivo na escola, [...] e envolvimento de alunos, famílias e funcionários na discussão do currículo (BARRETO; SOUSA, 2004, p.44).

As constatações apresentadas nessa categoria nos levam, mais uma vez, à conclusão de que apenas alguns municípios parecem estar obtendo sucesso na transição para os ciclos. Isso fica evidente na pesquisa de Jacomini (2014), que aponta que, com a implantação dos ciclos, a avaliação da aprendizagem precisa ser ressignificada.

Certamente, dentre todas as práticas e rotinas escolares, aquela que mais diretamente é 'abalada' com a implantação dos cic los é a avaliação, sendo sua ressignificação na prática escolar necessária, para tornar realidade a reorganização do processo educativo. (BARRETO; SOUSA, 2004, apud JACOMINI, 2014, p.813)

Ainda em relação à prática avaliativa, destacamos a pesquisa de Cunha (2004), realizada em Belém do Pará, em que ela mostrou que a prática das professoras nos ciclos de formação da Escola Cabana proporcionou a aprendizagem de seus alunos. Elas utilizaram a avaliação como instrumento para diagnosticar o que os alunos não sabiam e, a partir daí, fazer as intervenções necessárias:

[...] a avaliação é um instrumento de diagnóstico do processo ensinoaprendizagem que tem a função, entre outras, de ajudar, motivar e retroalimentar a aprendizagem do aluno e a prática pedagógica do professor; deve ser contínua e abranger todos os aspectos do desenvolvimento do aluno, respeitando suas características e diferenças individuais. (CUNHA, 2004, p.4)

O autor do estudo citado percebeu que, no trabalho das duas professoras, cujas práticas avaliativas foram selecionadas para a análise, não há fragmentação, visto que, no processo de ensino-aprendizagem e de avaliação, há interação, ou seja, são intercomplementares.

As análises deste tópico denotam que, para que a implementação dos ciclos na maioria das escolas municipais ocorra de maneira efetiva, são necessários ajustes, como o trabalho em equipe e o uso da avaliação de modo que contribua para a aprendizagem de todos os alunos. Como explicado, a avaliação deve servir como uma ferramenta para orientar os docentes (CUNHA, 2004; BARRETO; SOUSA, 2004), com a qual eles 
possam saber que pontos de sua prática precisam ser aprimorados, e não, como mais uma forma de excluir os alunos.

Conforme discutimos nos parágrafos anteriores, foram feitas algumas mudanças na forma de avaliar a aprendizagem em duas redes municipais na passagem de séries para ciclos. Elas colocaram em prática o conceito de avaliação formativa. Porém, a maioria das revisões mostra que é preciso melhorar e que existem discrepâncias entre os discursos e as práticas em algumas redes municipais.

\subsection{O processo de implementação dos ciclos}

Neste subtópico, mostramos algumas redes que executaram os ciclos de maneira artificial e outras que obtiveram sucesso. Barreto \& Sousa (2004) e Mainardes (2008) apontaram que a maioria das redes que implementaram os ciclos fizeram de maneira superficial. Dentre os vários aspectos da implementação, muitas escolas continuam com uma concepção equivocada de avaliação, como podemos confirmar nesta passagem:

[...] a implementação de programas de ciclos tem causado mudanças nas práticas avaliativas [...] No entanto, essas mudanças geralmente são incipientes e, portanto, mais ou menos distantes da retórica presente nas propostas oficiais, bem como de referenciais teóricos sobre avaliação da aprendizagem. [...] (MAINARDES, 2008, p.8).

É interessante notar que, no estudo de Jacomini (2014), que foi publicado seis anos depois, uma das principais conclusões acerca da avaliação foi a afirmação de que "se mudou o discurso, mas não, a prática". Então a escola e sua equipe devem, com urgência, estabelecer um horário e um espaço para a formação dos professores, para que, juntos, possam refletir sobre sua prática e aprimorá-la cada vez mais.

Em São Paulo, embora tenham sido criadas condições para dar suporte à organização do tempo escolar em ciclos, como, por exemplo, a criação de horários coletivos de trabalho na escola, conforme já mencionado, no período de 1992 (ano da implementação dos ciclos no ensino fundamental) ao início dos anos 2000 , continuou-se a reproduzir o sistema seriado, como confirma o trecho abaixo:

Sem a devida mobilização dos educadores em torno do projeto de implementação dos ciclos durante as várias gestões que se sucederam à sua introdução na rede, $[\ldots]$ os ciclos na capital de São Paulo tendem a funcionar como meros arranjos organizacionais que impedem a reprovação dos alunos (BARRETO; SOUSA, 2004, p. 40) 
Novamente temos a comprovação de que a maioria das redes que implementaram os ciclos o fizeram de maneira superficial, posto que ainda mantêm práticas características da organização seriada. No caso de São Paulo, os autores dizem queissosedeuporumaquestãopolítica“ [...] em virtude das vicissitudes decorrentes da alternância de partidos no poder e das diferenças ideológicas entre os grupos gestores que estiveram no comando do município" desde então (dos anos 1990 em diante) (BARRETO; SOUSA, 2004, p. 39).

Apesar do que foi mencionado nos parágrafos anteriores, em Porto Alegre, a implementação dos ciclos se diferenciou em vários aspectos. O envolvimento de alunos, das famílias e dos funcionários na discussão do currículo foi um dos aspectos que contribuiu de maneira positiva para a execução dos ciclos na referida rede. Lá, a avaliação era formativa, ou seja, ela serviu como base para redimensionar a ação pedagógica e educativa. $\mathrm{O}$ aluno não era considerado culpado pelo que não aprendia, ao contrário, o professor procurava identificar suas dificuldades e, a partir delas, direcionava seu trabalho. Isso pode ser evidenciado no seguinte fragmento:

[...] Destaque é dado à função formativa da avaliação, que deve servir de apoio ao redimensionamento da ação pedagógica e educativa, voltando-se para o conjunto da escola e não do aluno. (BARRETO; SOUSA, 2004, p.44)

Com base na citação acima, podemos afirmar que, ao contrário do que aconteceu em outros municípios, os docentes de Porto Alegre entenderam e aplicaram o conceito de avaliação formativa. Isso significa que eles utilizam os resultados das avaliações para reformular a prática pedagógica e, como consequência, o processo avaliativo (ESTEBAN, 2003). Como podemos perceber, nessa rede, o aluno não é culpado pelas dificuldades que apresenta.

\section{CONSIDERAÇÕES FINAIS}

Este trabalho visou responder a duas questões importantes para a implementação de um sistema educacional efetivamente não democrático, não seletivo e não excludente: O que fazer para melhorar a aprendizagem no sistema de ciclos? Qual deve ser o lugar da ação anual? A troca para ciclos exige mudanças na avaliação da aprendizagem e a reorganização do currículo. Assim, para que haja transformação não só nos discursos, mas também nas práticas de avaliação, é necessário propiciar tempo 
para que os docentes possam estudar e aperfeiçoar seu trabalho, como percebemos na rede de Porto Alegre e de Belo Horizonte.

Para reorganizar o currículo, é fundamental que equipes de professores e de gestores criem propostas pedagógicas diferenciadas e que os demais funcionários, os estudantes e suas famílias participem desse processo. Quanto ao lugar da avaliação da aprendizagem nesse novo modo de organizar o tempo em que os estudantes devem permanecer na escola, é muito importante que os todos os professores entendam o conceito de avaliação formativa e passem a dispor de mais um instrumento para direcionar seu trabalho.

Não é possível mudar ou analisar qualquer proposta de forma isolada sem inserila em um contexto mais amplo, porque acreditamos que a educação é muito complexa para que a mudança seja realizada somente em um aspecto, como foi a tendência das revisões analisadas, em que as redes só modificaram a avaliação. Existem outros aspectos fundamentais que não poderiam ser deixados de lado na implementação dos ciclos, como a prática pedagógica dos professores, sua formação e, principalmente, o entendimento deles para colocarem em prática essa nova forma de organizar o tempo e o espaço.

O estudo mostrou que já foram dados alguns passos em direção a essa importante reforma escolar e que ainda há um abismo entre a teoria e a prática. Assim, talvez uma questão interessante para outros trabalhos fosse: $O$ que as pesquisas de formação de professores cujo lócus é a escola apontam sobre a mudança da prática dos professores? O que elas nos indicam sobre o trabalho participativo de todos na construção de seu Projeto Político-pedagógico e a efetivação de sua proposta?

\begin{abstract}
The organization of school time in cycles, in some municipalities, was presented as an alternative to serial system in which, as we know, students have their learning assessed by evidence. However, even without the dreaded possibility of annual failure, the learning level of students is still lower than expected. Thus, this article aims to answer the following questions: How to improve the learning in the system cycles? What should be the place of learning assessment in this new organization of school time? In order to answer these questions, we performed an analysis of five revisions and one article on organization of school time in cycles in Brazil. These works have been published in nationally recognized events and reputable magazines in the scientific community, and converge to the view that the change from series to cycles requires that the concept of formative assessment is put into practice, as well as the reorganization of the curriculum. So, it is necessary to provide time for teachers to study and improve
\end{abstract}


their work. Moreover, to reorganize the curriculum, it is essential to develop differentiated pedagogical proposals by teams of teachers and administrators and to provide the participation of other employees, students and their families.

Keywords: Assessment. Forming cycle. Learning.

\section{REFERÊNCIAS}

BARRETO, Elba Siqueira de Sá; SOUSA, Sandra Zákia. Estudos sobre ciclos e progressão escolar no Brasil: uma revisão. Educação e pesquisa. São Paulo, v.30, n.1, p. 11-30, jan./abr. 2004. Disponível em: <http: //www.scielo.br $>$ Acesso em: 4 de jun. de 2015.

BARRETO, Elba Siqueira de Sá; SOUSA, Sandra Zákia. Reflexões sobre as políticas de ciclos no Brasil. Cadernos de Pesquisa, v. 35, n. 126, p. 659-688, set./dez. 2005. Disponível em: <http: //www. scielo.br> Acesso em: 4 de jun. de 2015.

CÂNDIDO, Alberto Gomes. Quinze anos de ciclos no ensino fundamental: um balanço das pesquisas sobre sua implantação. Revista Brasileira de Educação, $\mathrm{n}^{\circ}$ 25, Jan /Fev /Mar /Abr 2004. Disponível em: <http: //www.scielo.br> Acesso em: 4 de jun. de 2015.

CUNHA, Emmanuel Ribeiro. Práticas avaliativas bem sucedidas de professoras dos Ciclos de Formação da Escola Cabana de Belém. In: 27 $7^{\text {a }}$ Reunião Anual da ANPED, 2004, Caxambu. $27^{\mathrm{a}}$ Reunião Anual da Anped, 2004.

ESTEBAN, Maria Teresa. A dimensão reflexiva da avaliação. Entrevista concedida ao Programa Salto para o Futuro e publicada em 12 de fev. de 2014. Disponível em: <http://tvescola.mec.gov.br/tve/salto/interview> Acesso em: 27 de maio de 2015.

ESTEBAN, Maria Teresa. Avaliar: ato tecido pelas imprecisões do cotidiano. In: Regina Leite Garcia. (Org.). Novos olhares sobre a alfabetização. 1. ed. São Paulo: Cortez, 2001 p. 175-192.

ESTEBAN, Maria Teresa. Avaliação e fracasso escolar: questões para debate sobre a democratização da escola. Revista Lusófona de Educação, no 13, p. 123-124. Disponível em: < http://revistas.ulusofona.pt/index.php/rleducacao>Acesso em: 21 de maio de 2015.

ESTEBAN, Maria Teresa. Avaliação no cotidiano escolar. Rio de Janeiro: DP\&A, 2003, 5. ed. In: Maria Teresa Esteban (Org.). Avaliação: uma prática em busca de novos sentidos. Rio de Janeiro: DP\&A, 2003, 5. ed. p.7-27.

FREITAS, Ana Lúcia Souza de. Fundamentos, dilemas e desafios da avaliação na organização curricular por ciclos de formação. In: Maria Teresa Esteban (Org.). Escola, currículo e avaliação. 2. ed. São Paulo: Cortez, 2005, p. 57-81.

JACOMINI, Márcia Aparecida. Avaliação da aprendizagem em tempos de progressão continuada: O que mudou? Um estudo de teses e dissertações sobre o tema (20002010). Ensaio: aval. pol. públ. Educ., Rio de Janeiro, v. 22, n. 84, p. 807-828, jul./set. 2014. Disponível em: < http://www.scielo.br> Acesso em: 04 de jun. de 2015.

LUCKESI, Carlos Cipriano. Avaliação da aprendizagem: compreensão e prática. Entrevista concedida ao Jornal do Brasil e publicada em 21 de jul. 2000. Disponível em:

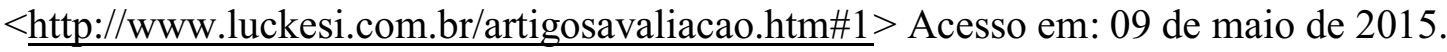


MAINARDES, Jefferson. A organização da escolaridade em ciclos: ainda um desafio para os sistemas de ensino. Cadernos de Pesquisa, v. 37, n. 132, p. 801-804, set./dez. 2007. Disponível em: $<$ http://www.scielo.br/pdf/> Acesso em: 19 de maio de 2015.

MAINARDES, Jefferson. A pesquisa sobre a organização da escolaridade em ciclos no Brasil (2000 - 2006): mapeamento e problematizações. Revista Brasileira de Educação v. 14 n. 40 jan./abr. 2009. Disponível em: <http: //www.scielo.br > Acesso em: 04 de jun. de 2015.

MAINARDES, Jefferson; GOMES, Ana Cláudia. Escola em ciclos e avaliação da aprendizagem: uma análise das contribuições de teses e dissertações (2000 a 2006). In: 31 ${ }^{a}$ Reunião Anual da ANPEd, 2008, Caxambu - MG. 31 ${ }^{a}$ Reunião Anual da Anped: Constituição Brasileira, Direitos Humanos e Educação, 2008. p. 1-16.

PARO, Vítor Henrique. Reprovação escolar? Não, obrigado. 15 fev. 2002. Disponível em: $<$ http://www.vitorparo.com.br/trabalhos-publicados/artigos/download/> Acesso em: 01de jun. de 2015.

Aprovado $\quad / 06 / 2016$

/06/2018 